MNEMOSYNE.

ZEIT UND ERINNERUNG IN HÖLDERLINS DENKEN 
Helmut Hühn

\section{MNEMOSYNE. \\ ZEIT UND ERINNERUNG IN HÖLDERLINS DENKEN}

Verlag J. B. Metzler

Stuttgart - Weimar 
Die Deutsche Bibliothek - CIP-Einheitsaufnahme

Hühn, Helmut:

Mnemosyne : Zeit und Erinnerung in Hölderlins Denken /

Helmut Hühn. - Stuttgart ; Weimar : Metzler, 1997

Zugl.: Berlin, Freie Univ., Diss., 1995

ISBN 978-3-476-01457-3

ISBN 978-3-476-01457-3

ISBN 978-3-476-03665-0 (eBook)

DOI $10.1007 / 978-3-476-03665-0$

Dieses Werk einschließlich aller seiner Teile ist urheberrechtlich geschützt. Jede Verwertung außerhalb der engen Grenzen des Urheberrechtsgesetzes ist ohne Zustimmung des Verlages unzulässig und strafbar. Das gilt insbesondere für Vervielfältigungen, Übersetzungen, Mikroverfilmungen und die Einspeicherung und Verarbeitung in elektronischen Systemen.

(C) 1997 Springer-Verlag GmbH Deutschland

Ursprünglich erschienen bei J. B. Metzlersche Verlagsbuchhandlung und Carl Ernst Poeschel Verlag GmbH in Stuttgart 1997 


\section{Inhalt}

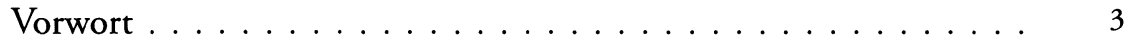

1. Einleitung .................... 5

1.1 Zum Ziel der vorliegenden Arbeit .............. 5

1.2 Zur Anwendung der entwicklungsgeschichtlichen Methode . . . . . . . . . . 7

1.3 Zur Gliederung der Arbeit . . . . . . . . . . . . . . . . . . . . 12

1.4 Bemerkungen zur philosophischen Rezeption Hölderlins im 20. Jahrhundert . . . . . . . . . . . . . . . . . . 16

2. Individualität versus Totalität, Leben versus Tod. Hölderlins Roman Hyperion oder der Eremit in Griechenland . . 23

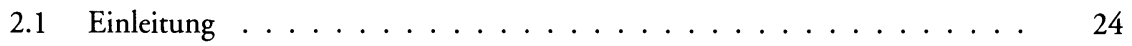

2.2 Zur Problemkonstellation des Hyperion . . . . . . . . . . . . . . . . . . . . . . 27

2.3 Der Tod in der "Anlage" und im "Plan" des Romans . . . . . . . . . . . . 33

2.4 Zur Stellung und Bedeutung der Scheltrede . . . . . . . . . . . . . . . . . . . 46

2.5 Die Trauerarbeit des Protagonisten . . . . . . . . . . . . . 54

3. Erinnerung und Dankbarkeit. Hölderlins Briefe Über Religion . . . . . . . . . . . . . . . . . 67

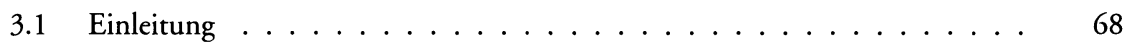

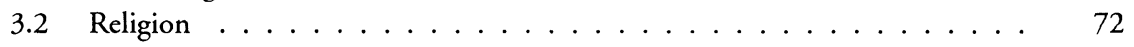

3.3 Erinnerung und Dank . . . . . . . . . . . . . . . . . . . . . . 91

3.4 Zur Datierung des Entwurfsfragmentes . . . . . . . . . . . . . . 100

4. Das untergehende Vaterland ... . Hölderlins Geschichtsphilosophie als Theorie der Erinnerung . . . . . . . . . . . . 117

4.1 Der Zeitgeist. . . . . . . . . . . . . . . . . . . . . . . . . . . . . . . . . . .

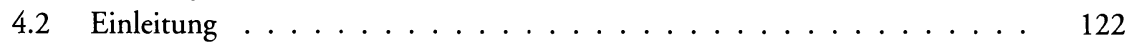

4.3 Geschichte als Darstellung der "Welt aller Welten" . . . . . . . . . . . . . 126

4.4 Die Krise des Übergangs . . . . . . . . . . . . . . . . . . . . . . . . . . . . . . . . . . . . . . . . . . . . . . .

4.5 Idealische Auflösung . . . . . . . . . . . . . . . . . . . . . . . . . . . . . . . . . . . . . . . . . . . . . . . . .

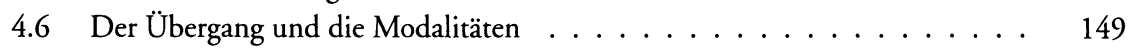

4.7 Freie Kunstnachahmung: "das Begreiffen ... des unbegreifbaren" . . . . . . . 153

4.7.1 Die Kunstleistung der Tragödie . . . . . . . . . . . . . . . . . . . . 153

4.7.2 Das untergehende Vaterland ... und Der Tod des Empedokles . . . . . . . . . . 158

4.8 Geschichtsphilosophie aus der Erfahrung der Zeit . . . . . . . . . . . . . 162 
5. Vergessen, Gedächtnis und Erinnerung im Kontext von Hölderlins Sophokles-Anmerkungen . . . . . . . . . . . . 165

5.1 Vorbemerkungen zu Hölderlins theoretischem Spätwerk . . . . . . . . . . . . 166

5.2 Einführung in die Sophokles-Anmerkungen . . . . . . . . . . . . . . . . 169

5.3 Einführung in Hölderlins Theorie des Tragischen in den Sophokles-Anmerkungen . . . . . . . . . . . . . . . . . . 178

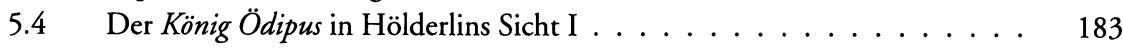

5.4 .1 Vorbemerkungen . . . . . . . . . . . . . . . . . . . . 183

5.4.2 Die "Verständlichkeit des Ganzen" . . . . . . . . . . . . . . . . . . . . 184

5.4.2.1 Die Deutung des Orakels . . . . . . . . . . . . . . . . . . . . . . . . . . . . . . . . . . . . . 184

5.5 Exkurs: Sokrates und Ödipus . . . . . . . . . . . . . . . . . . . 192

5.6 Die tragische Dynamik des Bewußtseins:

Selbstverlust und "närrischwilde(s) Nachsuchen nach einem Bewußtseyn" . 197

5.7 Hölderlins Theorie des Tragischen in den Anmerkungen zum Oedipus . . . . 211

5.8 Der König Ödipus in Hölderlins Sicht II. . . . . . . . . . . . . . . . . . . . . . . . . 218

5.8 .1 Die Blendung . . . . . . . . . . . . . . . . . . . . 222

5.9 Vergessen und Erinnerung im Kontext der tragischen Begegnung von Gott und Mensch . . . . . . . . . . . . . . . . . . . . 233

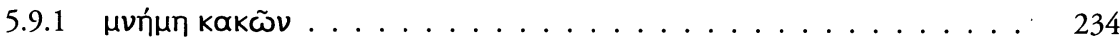

5.9 .2 Tragisches Vergessen . . . . . . . . . . . . . . . . . . . . . . 239

5.9.3 Die "furchtbare Muße einer tragischen Zeit» und der Einbruch der "reißenden Zeit" . . . . . . . . . . . . . . . . . . . . 243

5.10 Entwicklungsgeschichtliche Schlußbemerkungen zur Transformation der »idealischen Auflösung" im Kontext von Hölderlins später Konzeption des Tragischen . . . . . . . . . . . . . . . . . . .

6. "Am Kithäron aber lag / Elevtherä, der Mnemosyne Stadt.» Eine Ortsuntersuchung . . . . . . . . . . . . . . . 249

$6.1 \quad$ Einleitung. . . . . . . . . . . . . . . . 250

6.2 Die Vision vom Tod der Mnemosyne . . . . . . . . . . . . . . . 253

6.3 Poetische Übertragung als Trauerarbeit . . . . . . . . . . . . . . . . . . 256

6.4 "Elevtherä, der Mnemosyne Stadt" . . . . . . . . . . . . . . . . . . 261

6.5 Der Erinnerungsort Elevtherä . . . . . . . . . . . . . . . . . . . . . . 269

Literaturverzeichnis . . . . . . . . . . . . . . . . . . . . 273

Personenregister . . . . . . . . . . . . . . . . . . 291

Sachregister . . . . . . . . . . . . . . . . . . . . 295 
"Und immer

Ins Ungebundene gehet eine Sehnsucht. Vieles aber ist $\mathrm{Zu}$ behalten. Und Noth die Treue."

Friedrich Hölderlin, Mnemosyne 
Meinen Eltern und Dorothee 


\section{Vorwort}

Die vorliegende Untersuchung wurde Anfang des Jahres 1995 abgeschlossen und lag dem Fachbereich Philosophie und Sozialwissenschaften 1 der Freien Universität Berlin als Dissertation vor. Für die Publikation wurde sie geringfügig überarbeitet und aktualisiert.

Mein besonderer Dank gilt Herrn Professor Michael Theunissen, auf dessen philosophisches Wirken sich die vorliegende Schrift in mannigfacher Hinsicht bezogen weiß, und Frau Professor Anke Bennholdt-Thomsen, mit der mich seit mehreren Jahren ein Gespräch über Hölderlin verbindet, das das Fortschreiten der Untersuchung vielfältig gefördert hat.

Für Anregungen danke ich Herrn Professor Bernd Seidensticker, für manchen Rat und umsichtige Unterstützung Dr. Margarita Kranz, für Hinweise und Hilfe beim Korrekturlesen Frank Böhling, Katrin Grünepütt, Dr. Thomas Isermann, Dr. Caroline Neubaur, Marcello Pocai, Dr. Martin Schulze Wessel und Martin Vöhler. Wenn ich im Verstehen Hölderlins weitergekommen bin, so verdanke ich das auch Dr. Tilman Heisterhagen.

Danken möchte ich ferner dem Land Berlin für die finanzielle Unterstützung der Promotion, der Geschwister Boehringer Ingelheim Stiftung für die Gewährung eines großzügigen Druckkostenzuschusses und dem Verlag, der sich des Buches mit Sorgfalt angenommen hat.

Berlin, im Sommer 1996

Helmut Hühn 